Leandro Dias de Godoy Maia ${ }^{1}$

Nicácio Dieger Silva ${ }^{2}$

Patrícia Helena Costa Mendes ${ }^{3}$

\section{Síndrome de Burnout em agentes comunitários de saúde: aspectos de sua formação e prática}

\author{
Burnout syndrome among community health agents: aspects of \\ their training and practice
}

${ }^{1}$ Médico do Trabalho, mestre em Cuidado Primário em Saúde e docente da Universidade Estadual de Montes Claros - Montes Claros, Minas Gerais, Brasil.

${ }^{2}$ Acadêmico do Curso de Medicina - Centro de Ciências Biológicas e da Saúde da Universidade Estadual de Montes Claros - Montes Claros, Minas Gerais, Brasil.

${ }^{3}$ Cirurgiã-dentista, especialista em Odontologia do Trabalho, mestre em Cuidado Primário em Saúde e docente do programa PET-Saúde da Universidade Estadual de Montes Claros - Montes Claros, Minas Gerais, Brasil.

Contato:

Leandro Dias de Godoy Maia

Rua João Souto, 540 - Apto. 801

Montes Claros - Minas Gerais - Brasil

Cep: 39.400-081

E-mail:

leogodoymoc@hotmail.com
Recebido: 14/07/2010

Revisado: 02/05/2011

Aprovado: 12/05/2011

\section{Resumo}

A síndrome de burnout tem recebido destaque em recentes pesquisas por representar não apenas um agravo à saúde do profissional, mas também um risco aos indivíduos por ele assistidos, principalmente em atividades nas quais o contato humano é um componente preponderante. O objetivo deste estudo é analisar a manifestação de burnout em agentes comunitários de saúde (ACS) a partir da literatura revisada, dando ênfase a aspectos de sua formação e prática. Procedeu-se a uma pesquisa de referencial teórico a partir de publicações encontradas na base de dados da Literatura Latino-Americana e do Caribe em Ciências da Saúde (Lilacs). Importantes fontes de estresse ocupacional levantadas nas referências foram: a função de elo entre serviço e comunidade exercida por este profissional, a proximidade emocional com a população e o contato direto com os problemas socioeconômicos do território. Foi averiguado também que a formação do agente, no que tange aos conhecimentos humano-sociais, é ainda insuficiente. Conclui-se que estas questões suscitam mudanças na formação dos agentes e nas suas condições de trabalho, sendo que os benefícios destas medidas refletir-se-ão também sobre a saúde da população assistida, e que o limitado número de pesquisas empíricas sobre ACS e burnout encontradas para este estudo prova a necessidade de pesquisas adicionais para consolidação destes conhecimentos e futuras mudanças na abordagem destes profissionais.

Palavras-chave: esgotamento profissional; saúde ocupacional; auxiliares de saúde comunitária; Programa Saúde da Família.

\begin{abstract}
Recent studies have given special attention to burnout as an occupational outcome that affects both professionals as well as those who were cared by them, especially in areas where human contact among people is predominant. The purpose of this study is to analyze, through reviewed literature, the manifestation of burnout syndrome among Community Health Agents (CHA), emphasizing the aspects of their training and practice. The important sources of occupational stress among Brazilian CHA according to the literature searched in the Latin American and Caribbean Health Sciences (Lilacs) bibliographic index were: their roll as a link between community and health services, their emotional proximity with the assisted population, and their close contact with the socio-economic problems of their environment. It was also observed that CHA training is unsatisfactory regarding humanities and social science knowledge. These issues bring up the need of changes in CHA training and working conditions, which should also benefit the workers they care for. In addition to it, the limited number of available research on CHA and burnout indicates the need for studies to consolidate these findings and the future changes in training and praxis of these agents.
\end{abstract}

Keywords: burnout; occupational health; community health agents; Family Health Program. 


\section{Introdução}

A atividade laboral e o estresse físico/psicológico possuem relações há muito estabelecidas (MURTA, 2005). Entretanto, os efeitos do estresse gerado no ambiente de trabalho sobre a saúde do trabalhador têm merecido destaque crescente tanto por parte dos pesquisadores e do sistema de saúde, quanto por parte da mídia e dos próprios trabalhadores (SOUZA; SILVA, 2002).

Neste contexto, a síndrome de burnout, síndrome do esgotamento profissional ou estafa profissional, destaca-se entre as recentes pesquisas, representando uma entidade própria. Trata-se de uma síndrome que engloba sensações de ineficácia e desapego ao trabalho, atingindo trabalhadores expostos a estressores crônicos presentes no ambiente laboral (CASTILLO RAMÍREZ, 2001; SCHWARTZMANN, 2004; MASLACH, 2009).

A síndrome de burnout é reconhecidamente um agravo relacionado às áreas de trabalho nas quais o contato humano é um componente de destaque, ressaltando-se professores, enfermeiros, médicos, assistentes sociais e outros profissionais da saúde e de serviços humanos (CASTILLO RAMÍREZ, 2001; SOUZA; SILVA, 2002; TRIGO; TENG; HALLAK, 2007; TELLES; PIMENTA, 2009). Na área da saúde, o burnout assume características ainda mais extensas, pois, uma vez que acomete um profissional responsável pela saúde de outro ser humano, pode, por consequência, atingir indiretamente a saúde deste último também (LINZER et al., 2005; FIGUEIREDO et al., 2009). Por esta peculiaridade, vem sendo dada uma crescente atenção à relação entre burnout e trabalhadores da saúde, aos aspectos do trabalho em saúde que contribuem para o seu desenvolvimento e às consequências desse estresse crônico sobre a saúde do profissional, sobre a qualidade do seu atendimento e sobre a saúde de seus pacientes (LINZER et al., 2005).

Até o presente momento, os estudos disponíveis na literatura são focados em médicos e enfermeiros, de forma que pouco se sabe, senão empiricamente, sobre a relação entre burnout e outros profissionais de saúde. Dentre estes, destaca-se o agente comunitário de saúde (ACS), um profissional relativamente novo no contexto da saúde pública, singular e essencial à nova estruturação da atenção primária proposta para o país (NASCIMENTO, 2008; DIAS, 2008; VASCONCELLOS; COSTA-VAL, 2008; FIGUEIREDO et al., 2009).

O propósito deste estudo consiste em avaliar, baseado em dados da literatura, a relação existente entre a síndrome do esgotamento profissional e o agente comunitário de saúde, abordando questões referentes à sua formação e à prática de sua profissão que possam estar relacionadas ao surgimento desta síndrome. Para tanto, pretende-se, por um lado, expor e debater as conexões entre esta síndrome e este profissional, já abordadas na literatura; por outro, e paralelamente, explorar os conhecimentos existentes acerca do burnout dentre as publicações legais e científicas relativas à ação e à formação dos ACS com o objetivo de levantar hipóteses adicionais.
Esta revisão tem ainda o intuito de levantar e avaliar a disponibilidade de informações científicas presentes acerca do tema em questão.

\section{Material e métodos}

O presente ensaio constitui-se em uma reflexão circunstanciada sobre a literatura produzida a respeito do tema. Para a obtenção do referencial teórico, foi realizada, através da Biblioteca Virtual em Saúde (BVS), uma consulta à base de dados da Literatura Latino-Americana e do Caribe em Ciências da Saúde (Lilacs), tendo sido utilizados os descritores DeCS/MeSH "Visitadores Domiciliares", "Auxiliares de Saúde Comunitária" e "Esgotamento Profissional”, considerando "qualquer descritor (OR)".

Por meio deste levantamento, foram obtidas 462 referências. Procedeu-se a princípio à leitura dos títulos das referências, excluindo-se, então, aquelas que indubitavelmente não abordavam um dos temas em questão. Excluíram-se, então, os trabalhos que discursavam sobre agentes comunitários de saúde de outros países que não o Brasil devido às peculiaridades da inserção prática deste profissional em nosso país. Em seguida, foram analisados os resumos dos artigos restantes, sendo selecionados aqueles que interligavam o tema central "agente comunitário de saúde" aos aspectos relacionados à sua saúde/qualidade de vida, ao seu processo de trabalho, aos riscos inerentes à sua profissão, à sua formação/ educação ou às suas concepções sobre estes próprios temas. Incluíram-se tanto trabalhos de revisão, quanto trabalhos empíricos. Foram inclusos, ainda, artigos de revisão de literatura sobre a síndrome de esgotamento profissional. Publicações relacionando a síndrome de esgotamento profissional às classes profissionais específicas que não os agentes comunitários de saúde foram excluídas. Não houve critérios relativos à data de publicação dos trabalhos. Posteriormente à pesquisa no banco de dados, procedeu-se à busca ativa entre as referências bibliográficas dos artigos obtidos com o intuito de identificar trabalhos de relevância que não houvessem sido captados no levantamento inicial. Ao final, foram elencadas 35 publicações, subdivididas nas categorias temáticas: "revisões sobre a síndrome de burnout", "formação do ACS”, "prática do ACS”, “qualidade de vida do ACS”, "manuais e publicações legais sobre o ACS" e "ACS e estresse ocupacional/síndrome de burnout”.

\section{Discussão}

Em 1974, em um artigo intitulado Staff Burnout, o psiquiatra Herbert J. Freudenberger fez uso da expressão burnout para definir os sentimentos de fracasso, exaustão e incapacidade observados em voluntários jovens e idealistas que trabalhavam em uma clínica para pacientes dependentes de substâncias psicoativas na cidade de Nova Iorque (FREUDENBERGER, 1974). Embora a expressão já houvesse sido usada para descrever achados 
semelhantes a esses, foi a partir dessa publicação que o neologismo adquiriu maiores proporções no meio científico. O termo, em inglês, é formado pela justaposição de duas palavras: burn, relacionada ao verbo "queimar"; e out, entendida como "totalmente", "até o fim". A "erosão psicológica” característica do que veio a ser mais bem definido como uma síndrome é associada à imagem de uma chama que se reduz às cinzas (MASLACH, 2009).

Nas línguas latinas, têm sido usados os termos "queimar-se" ou "consumir-se" quando em substituição à expressão anglo-saxônica, ainda que, em sua maioria, os trabalhos façam uso do termo original, sem tradução (CASTILLO RAMÍREZ, 2001; SCHWARTZMANN, 2004). Ademais, é sinônima a denominação "síndrome do esgotamento (ou estafa) profissional” (SOUZA; SILVA, 2002).

A Classificação Estatística Internacional de Doenças e Problemas Relacionados à Saúde, em sua décima revisão (CID-10), versão 2008, traz o assunto sob o código “Z73.0 Esgotamento: estado de exaustão vital”, dentro do agrupamento "Z70-Z76 Pessoas em contato com os serviços de saúde em outras circunstâncias”, pertencente ao capítulo XXI: "fatores que influenciam o estado de saúde e o contato com os serviços de saúde" (ORGANIZAÇÃO MUNDIAL DA SAÚDE, 2008).

No Brasil, a síndrome foi oficialmente adicionada às doenças relacionadas à saúde do trabalhador através do Decreto $n^{\circ} 3.048$, de 6 de maio de 1999. Em seu Anexo II, o decreto apresenta-a na subdivisão "Transtornos mentais e do comportamento relacionados com o trabalho" como "Sensação de estar acabado ("Síndrome de Burn-Out', 'Síndrome do Esgotamento Profissional')”, tendo como fatores de risco de natureza ocupacional "ritmo de trabalho penoso" e "outras dificuldades físicas e mentais relacionadas ao trabalho” (BRASIL, 1999). A Portaria Federal nº 1.339/GM-MS, de 18 de novembro de 1999, que institui a lista de doenças relacionadas ao trabalho, mantém esta mesma redação. No ano de 2001, surge a publicação "Doenças Relacionadas ao Trabalho - Manual de Procedimentos para os Serviços de Saúde”, uma coautoria do Ministério da Saúde e da Organização Pan-Americana da Saúde/Brasil que aborda o tema de maneira mais ampla, incluindo fatores de risco, diagnóstico e tratamento.

A caracterização da síndrome, todavia, vai além de suas definições legais. Tal caracterização é complexa, não apresentando um consenso entre os estudiosos acerca do tema. Depara-se, na literatura, com uma variedade de opiniões e modelos que buscam delinear os componentes da síndrome do esgotamento profissional. Pode-se dizer, contudo, que a opinião mais utilizada foi introduzida por Maslach et al. em seus trabalhos (CASTILLO RAMÍREZ, 2001; SCHWARTZMANN, 2004). Sob esta autoria, a síndrome de burnout é composta por três sintomas ou, mais apropriadamente, três dimensões: exaustão emocional, despersonalização e baixa realização profissional - formando o que é conhecido como modelo multidimensional (MASLACH, 2009).
A exaustão emocional, o componente pessoal da síndrome, é representada por uma sensação de desânimo, fraqueza e falta de energia (esgotamento) aliada ao sentimento de incapacidade de lidar com as atividades rotineiras da prática laboral (CASTILLO RAMÍREZ, 2001; TELLES; PIMENTA, 2009). Podem estar presentes outros sintomas psíquicos - como irritabilidade, raiva, impaciência, desesperança e depressão - e somáticos como cefaleia, mialgia, náuseas e distúrbios do sono. A baixa do sistema imune consequente desses sintomas pode predispor o indivíduo a doenças infecciosas, especialmente de etiologia viral (CASTILLO RAMÍREZ, 2001; TRIGO; TENG; HALLAK, 2007).

A despersonalização é a consequência do distanciamento e das atitudes negativas, indiferentes ou impacientes adotados pelo profissional que sofre desta síndrome (SILVA, 2008). Esta dimensão é a responsável pelo efeito indireto da síndrome de burnout sobre as pessoas - e sua saúde - que, na condição de usuárias do serviço prestado pelo indivíduo afetado pelo esgotamento profissional, têm contato com este. Porém, é importante a compreensão deste componente como um fator de proteção adotado naturalmente pelo sujeito esgotado (TELLES; PIMENTA, 2009).

A baixa realização profissional é acompanhada de sensações de incapacidade, insuficiência, desmotivação e insatisfação para com o trabalho (TELLES; PIMENTA, 2009). O indivíduo pode acreditar que seus atos não têm valor (TRIGO; TENG; HALLAK, 2007).

Questiona-se, porém, a necessidade da presença destes três componentes, uma vez que a maneira pela qual a síndrome se manifesta varia substancialmente entre os indivíduos (SCHWARTZMANN, 2004). A despeito disso, os autores concordam, como já abordado, que a síndrome de burnout desenvolve-se a partir da exposição crônica a estressores interpessoais presentes no ambiente de trabalho. A síndrome é uma resposta adaptativa a este estresse crônico estável. É também consenso, desde os primeiros estudos, que a síndrome é predominante em profissionais cujas atividades necessitem contato emocional direto e constante com os usuários daquele determinado serviço, donde se citam os trabalhadores das áreas da saúde, da assistência social, das religiões, da educação, da segurança pública, dentre outras (MASLACH, 2009). Ora, é justamente esta forma de contato (característica destas profissões, nas quais, sendo comum a presença constante de situações de sofrimento, geram-se relações permeadas por dó, medo, frustração e outras formas de tensão entre o profissional e o assistido) que predispõe à exposição crônica a situações de estresse interpessoal (VASCONCELLOS; COSTA-VAL, 2008). Esta predisposição é ainda mais evidente ao se avaliar que estas mesmas profissões são embasadas em filosofias humanísticas, sob as quais os profissionais (e suas expectativas) são formados, mas que frequentemente se contrapõem à realidade da prática do serviço (TELLES; PIMENTA, 2009). Não obstante, a síndrome de burnout tem sido recentemente relacionada a ocupa- 
ções de outras áreas como consequência do processo de focalização do atendimento no cliente (MASLACH, 2009).

As causas desta síndrome, que devem ser mais bem compreendidas como fatores de risco, são múltiplas. Estudos realizados com este intuito demonstram que estão envolvidas questões relacionadas ao próprio indivíduo, ao ambiente de trabalho e até mesmo à estrutura social que ampara este indivíduo (CASTILLO RAMÍREZ, 2001; MURTA, 2005; TRIGO; TENG; HALLAK, 2007). Dentre os fatores de risco pessoais, podem-se citar comportamentos competitivos, esforçados, impacientes, superenvolvidos, pessimistas, perfeccionistas, passivos e aqueles que alimentam grandes expectativas em relação à própria profissão. Cabe assinalar que alguns estudos indicam que pessoas com nível cultural mais elevado, solteiros, viúvos e divorciados também estão mais propensos (TRIGO; TENG; HALLAK, 2007). Fatores laborais incluem sobrecarga, trabalho em turnos/noturno, suporte organizacional precário, relacionamento deficitário com os colegas, falta de autonomia, burocracia excessiva e contato próximo entre profissional e usuário, em especial quando aquele, por meio de sua profissão, tem responsabilidades sobre a vida deste. Deve ser considerado, ainda, o amparo familiar e social do qual dispõe o indivíduo, bem como outras questões sociais e culturais que, influenciando o pensar e o agir deste, possam predispô-lo a comportamentos de risco. Assim, a forma como o indivíduo responde ou enfrenta estas situações (de risco) influenciam no surgimento ou não da síndrome, bem como no modo pelo qual ela irá se manifestar (MURTA, 2005). Por meio desses conhecimentos, é possível compreender porque a simples presença do estresse ocupacional não é sinônimo de desenvolvimento da síndrome de burnout, no aspecto holístico de sua definição (CAMELO; ANGERAMI, 2004; SCHWARTZMANN, 2004).

As consequências da síndrome de burnout, por sua vez, também podem ser vistas nestas mesmas três esferas. Os efeitos sobre o próprio indivíduo entrelaçam-se com os sintomas descritos para a síndrome: podem surgir manifestações somáticas, tais como cefaleias, dores osteomusculares, distúrbios gastrointestinais, cardiovasculares (incluindo risco aumentado para infarto agudo do miocárdio) e do sono, disfunções sexuais e menstruais, associadas, como mencionado, a uma maior predisposição a infecções, decorrente da baixa do sistema imune; e psíquicas, a citar distúrbios de atenção, concentração e memória, labilidade emocional, baixa autoestima, predisposição ao consumo de drogas (lícitas e ilícitas) e ao suicídio, dentre outras (CASTILLO RAMÍREZ, 2001; CAMELO; ANGERAMI, 2004; TRIGO; TENG; HALLAK, 2007). Há um maior número de absenteísmos ao trabalho que, associado a uma queda da qualidade dos serviços prestados pelo indivíduo esgotado, pode trazer prejuízos mensuráveis à instituição para a qual este trabalha. É importante lembrar que o sujeito esgotado pouco se empolga, se esforça ou estimula sua criatividade. Há negligência, imprudência, mau atendimento e ou- tros erros (SCHWARTZMANN, 2004; TRIGO; TENG; HALLAK, 2007). Esses mesmos malefícios que atingem a instituição refletem-se também em seus clientes (CAMELO; ANGERAMI, 2004). Enquanto o mau atendimento pode repercutir sobre a saúde psíquica do usuário, os erros, independentemente de sua natureza, podem trazer consequências ainda mais sérias. Ao se falar de assistência à saúde e erro médico, o assunto adquire destaque adicional.

Conhecer, assim, a definição, os componentes, as causas e os prejuízos da síndrome de burnout ajuda a compreender a relação entre esta síndrome e os ACS dentro de suas significativas peculiaridades. Considerando o ACS sob a ótica de singularidade que lhe é atribuída, Nunes et al. (2002) definem-no como um profissional "híbrido" e "polifônico", de maneira que, funcionando como um mediador entre a comunidade atendida e o serviço de saúde (o que lhe é possibilitado pela sua formação baseada em conhecimentos biomédicos contraposta à sua origem comunitária local), acaba se situando em uma posição de destaque na consolidação e no funcionamento da Estratégia Saúde da Família (ESF). De fato, é recorrente nos diversos trabalhos a caracterização do ACS como um articulador e formador do elo entre serviço de saúde e comunidade (SILVA, 2001; NUNES et al., 2002; CAMELO; ANGERAMI, 2004; KLUTCHOVSKY et al., 2007; NASCIMENTO;DAVID, 2008;VASCONCELLOS; COSTA-VAL, 2008; NASCIMENTO; CORREA, 2008; BORNSTEIN; STOTZ, 2008; SILVA, 2008; FIGUEIREDO et al., 2009; FERREIRA et al., 2009; TELLES; PIMENTA, 2009). Assim, ele, ao mesmo tempo, vivencia as contradições entre estas duas esferas e possibilita seu diálogo e compreensão mútua (NUNES et al., 2002). Não por acaso, esta é, historicamente, a ideia essencial do ser ACS (SILVA; DALMASO, 2002; TOMAZ, 2002).

O ACS não se resume, porém, a apenas um elemento de comunicação entre servidores e usuários. Em verdade, é o representante de uma classe de trabalhadores da saúde relativamente nova à qual é delegado o cumprimento de uma série de funções. O surgimento desta classe no Brasil remonta à instituição do Programa de Agentes Comunitários de Saúde (PACS), em 1991, e, posteriormente, do Programa Saúde da Família (PSF) - hoje definido como uma estratégia (portanto, ESF) -, em 1994. A ESF constitui o alicerce da atual política de Atenção Primária à Saúde (APS) adotada pelo Sistema Único de Saúde (SUS) (BRASIL, 2006a). Ideologicamente, a ESF é delineada por uma série de princípios que se encontram com aqueles definidos para o SUS, atuando por meio de ações de prevenção de agravos e promoção e recuperação da saúde, de maneira integral e contínua, em uma abordagem focada na comunidade e nas suas variáveis (BRASIL, 2006a). Em termos organizacionais, os municípios são divididos em territórios e estes, em microáreas. Cada território recebe uma Equipe de Saúde da Família (que, por definição, deve conter, no mínimo: médico, enfermei- 
ro, auxiliar ou técnico de enfermagem e agentes comunitários de saúde). Ressalta-se que cada microárea fica a cargo de um ACS (BRASIL, 2006a).

As atribuições deste profissional estão diferentemente enumeradas em duas publicações legais: na Lei $\mathrm{n}^{\mathrm{o}}$ 11.350, de 5 de outubro de 2006 (Brasil, 2006b); e no Anexo I da Portaria nº 648-GM, de 28 de março de 2006 (BRASIL, 2006a). A Portaria, em seu Anexo I, traz como atribuições específicas do ACS:

I - desenvolver ações que busquem a integração entre a equipe de saúde e a população adscrita à UBS, considerando as características e as finalidades do trabalho de acompanhamento de indivíduos e grupos sociais ou coletividade; II - trabalhar com adscrição de famílias em base geográfica definida, a microárea; III - estar em contato permanente com as famílias desenvolvendo ações educativas, visando à promoção da saúde e a prevenção das doenças, de acordo com o planejamento da equipe; IV - cadastrar todas as pessoas de sua microárea e manter os cadastros atualizados; V - orientar famílias quanto à utilização dos serviços de saúde disponíveis; VI - desenvolver atividades de promoção da saúde, de prevenção das doenças e de agravos, e de vigilância à saúde, por meio de visitas domiciliares e de ações educativas individuais e coletivas nos domicílios e na comunidade, mantendo a equipe informada, principalmente a respeito daquelas em situação de risco; VII - acompanhar, por meio de visita domiciliar, todas as famílias e indivíduos sob sua responsabilidade, de acordo com as necessidades definidas pela equipe; e VIII - cumprir com as atribuições atualmente definidas para os ACS em relação à prevenção e ao controle da malária e da dengue, conforme a Portaria $n^{\circ}$ 44/GM, de 3 de janeiro de 2002. (BRASIL, 2006a).

A Portaria informa, ainda, que devem somar-se a estas atribuições aquelas aplicáveis a todos os profissionais das Equipes de Saúde da Família, ditas atribuições globais. Estas, em síntese, apresentam-se como uma reescrita mais abrangente e detalhada dos comentados princípios da ESF.

A Lei, por sua vez, levanta em seu texto que são atividades do ACS:

I - a utilização de instrumentos para diagnóstico demográfico e sócio-cultural da comunidade; II - a promoção de ações de educação para a saúde individual e coletiva; III - o registro, para fins exclusivos de controle e planejamento das ações de saúde, de nascimentos, óbitos, doenças e outros agravos à saúde; IV - o estímulo à participação da comunidade nas políticas públicas voltadas para a área da saúde; V - a realização de visitas domiciliares periódicas para monitoramento de situações de risco à família; e VI - a participação em ações que fortaleçam os elos entre o setor saúde e outras políticas que promovam a qualidade de vida. (BRASIL, 2006b).

Embora se apreciem vocábulos diferentes na composição de ambos os textos, as ideias apresentadas são perceptivelmente as mesmas. Aborda-se a função de elemento coesivo entre a equipe de assistência à saúde e a população, já mencionada, e dá-se ao ACS a função coo- perativa de trabalhar nas ações de prevenção de agravos e promoção da saúde, em seu planejamento e execução, de maneira diagnóstica e preventiva. Citam-se, nesse contexto, a visitação domiciliar, a criação e a manutenção de uma base de dados locais e a utilização de ferramentas de diagnóstico demográfico, atividades pelas quais esses propósitos devem ser alcançados. Esta definição legal, embora completa e certamente útil para este fim, torna-se vaga quando de sua aplicabilidade prática.

Indo além desta abordagem, o ACS é um profissional da área da saúde que deve estar apto a realizar diversos procedimentos, como pesar e aferir a altura de crianças, conferir-lhes o cartão vacinal e promover a complexa arte da educação em saúde em temas variados, especialmente nos campos da alimentação, da higiene e do autocuidado (NUNES et al., 2002; FERREIRA et al., 2009). É, portanto, uma profissão composta por afazeres técnicos.

O ACS deve estar também apto a, pelo que lhe conferem as características da sua atuação, deparar-se com situações precárias de saúde e vida, bem como de diferentes formas de desigualdade social; aptidões estas não adquiridas sequer pela maioria dos outros profissionais da área da saúde, que têm formação acadêmica (SILVA; DALMASO, 2002; TELLES; PIMENTA, 2009). Sendo assim, é uma profissão que exige do ACS “a capacidade de enfrentar o dinamismo dos problemas da realidade sanitária” (KLUTCHOVSKY et al., 2007, p. 177).

Por meio da abordagem familiar, o ACS é também o principal responsável da equipe em levar a atenção à saúde para a esfera domiciliar (NUNES et al., 2002; FERREIRA et al., 2009). Sob este ato, há também outras duas finalidades: a de passar à população uma maior capacidade de enfrentamento de seus próprios problemas sanitários, através da transmissão de conhecimentos em saúde (SILVA, 2001; NUNES et al., 2002; BORNSTEIN; STOTZ, 2008), e a de, no sentido inverso, retransmitir ao serviço de saúde as informações que, tendo valor diagnóstico ou estatístico para a equipe, sejam colhidas ou percebidas pelo ACS em suas visitas (DUARTE; SILVA; CARDOSO, 2007; NASCIMENTO; CORREA, 2008; BORNSTEIN; STOTZ, 2008). Tal incumbência traz uma aproximação duradoura e muitas vezes íntima com os moradores, que, associada ao fato de o ACS já residir naquela mesma área, traz uma inegável carga de intenso envolvimento emocional (CAMELO; ANGERAMI, 2004; VASCONCELLOS; COSTA-VAL, 2008; BORNSTEIN; STOTZ, 2008; BACHILLI; SCAVASSA; SPIRI, 2008; FERREIRA et al., 2009).

Pelo exposto, tem-se, sinteticamente, uma visão do processo de trabalho do ACS. Assim, cabe aqui o relacionar ao que já foi abordado sobre a síndrome de burnout. Em primeiro lugar, cumpre analisar a unânime função de elo entre serviço e comunidade, saber científico e saber popular. Esta é, sem dúvida, a característica do ACS mais benéfica tanto ao serviço, quanto à comunidade. A união entre os dois saberes permite que ele faça com que um polo entenda melhor o ou- 
tro, possibilitando às ações desenvolvidas um alcance maior. Entretanto, é esta mesma característica que o põe em outra posição singular: a de ser duplamente cobrado (SILVA; DALMASO, 2002; VASCONCELLOS; COSTA-VAL, 2008; FIGUEIREDO et al., 2009). Tanto a equipe, como a população depositam sobre o ACS anseios e expectativas que, cronicamente, tornam-se fortes estressores. A necessidade de constante autoadaptação imposta pela função de mediador traduz uma instabilidade na maneira de trabalho que também pode transformar-se em fonte de estresse laboral crônico (KLUTCHOVSKY et al., 2007).

O que permite ao ACS entender-se como elo é, principalmente, a sua residência no território atendido, isto é, por definição legal, um dos requisitos para que um indivíduo possa vir a ingressar na profissão (BRASIL, 2006b). A função de tradutor deve ser entendida como possível não pelo fato do ACS ser um profissional que segue o caminho de leigo a profissional da saúde sem, necessariamente, passar por uma formação acadêmica o que tornaria desnecessária sua residência no território -, mas sim pelo fato dele compartilhar com a comunidade atendida o mesmo padrão social, cultural e, principalmente, linguístico, o que só é conseguido a partir deste requisito (VASCONCELLOS; COSTA-VAL, 2008; FERREIRA et al., 2009). Este compartilhamento, por sua vez, também coloca o ACS em uma posição de vantagem no entendimento das variáveis sociais e demográficas que predispõem o território e a população em questão a determinados agravos (FERREIRA et al., 2009).

Contrariamente, devido à proximidade física, social e, às vezes, emocional com a comunidade, o ACS acaba por continuar o desenvolvimento de suas atividades durante o seu tempo livre - em finais de semana, feriados ou mesmo no seu dia a dia, ultrapassando o horário estabelecido para sua função (AZAMBUJA et al., 2007; SILVA, 2008; WAI; CARVALHO, 2009). A população tende a solicitar, com naturalidade, os serviços do ACS em parte devido à imagem de um profissional que está sempre disposto a ajudar, comumente associada ao agente (VASCONCELLOS; COSTA-VAL, 2008; NASCIMENTO; CORREA, 2008). Além disso, as atividades que o ACS exerce, na prática, frequentemente extrapolam as obrigações da sua profissão (NASCIMENTO; CORREA, 2008; NASCIMENTO; DAVID, 2008; FERREIRA et al., 2009), especialmente devido ao fato de suas atribuições, quando expostas, serem mal delimitadas (TOMAZ, 2002). Estes fatores causam uma clara sobrecarga de trabalho ao agente, o que, como demonstrado, é um importante fator de risco para o desenvolvimento da síndrome de burnout. Nascimento e David (2008), assim como Wai e Carvalho (2009), apontaram, em seus estudos, que muitos ACS queixavam-se dessa demanda adicional, mas a maioria não conseguia impor limites aos pedidos da população, alimentando a imagem do agente "sempre disposto a ajudar".

A literatura ressalta também o sentimento de impotência descrito pelos ACS frente aos problemas econômicos e sociais da comunidade (DUARTE; SILVA;
CARDOSO, 2007; AZAMBUJA et al., 2007; NASCIMENTO; DAVID, 2008; BACHILLI; SCAVASSA; SPIRI, 2008; SILVA, 2008). Este sentimento representa, em outras palavras, uma grande expectativa depositada sobre a profissão por parte dos próprios agentes, superior à sua capacidade de resolução. Ora, esta expectativa desproporcional é, como citado anteriormente, um dos principais fatores de risco para o desenvolvimento do esgotamento profissional e reflete, novamente, uma incompreensão dos limites de atuação do ACS.

Nesta mesma linha, Bachilli, Scavassa e Spiri (2008) observaram em sua pesquisa que a maioria dos ACS desconhecia, à época de seu ingresso nesta profissão, as características e as atribuições do trabalho que viriam a desenvolver. Muitos acreditavam que era este um trabalho mais burocrático, com pouca aproximação à comunidade e ao restante da própria equipe de saúde. Relatam também que alguns dos ACS entrevistados entraram para a ESF no momento de sua implementação naqueles municípios, de forma que este contexto "era algo novo para eles, para os gestores e para os usuários" (BACHILLI; SCAVASSA; SPIRI, 2008, p. 54). Os autores incrementam o assunto com a aferição de que, na verdade, muitos profissionais da saúde (inclusive servidores do SUS) ainda desconhecem as verdadeiras funções deste profissional. É fato que estes aspectos tendem a mudar positivamente com o natural avanço da área de cobertura da ESF, do seu conhecimento por parte da população e da sua divulgação na mídia. Todavia, é importante lembrar que a síndrome de burnout é caracteristicamente crônica e que situações estressantes são, muitas vezes, cumulativas. Assim, este choque entre expectativa e realidade enfrentada por certos ACS no passado pode ter sido mais uma importante fonte de estresse que culminou no surgimento da síndrome percebida hoje em alguns destes profissionais. Merece, portanto, ser lembrada e abordada sempre que um trabalho terapêutico for feito com estes profissionais no âmbito desta síndrome.

A proximidade emocional entre agentes e comunidade também é outra possível fonte de estresse. Os ACS sentem, por vezes, maiores dificuldades na abordagem de tabus ou assuntos polêmicos importantes à saúde, pois as pessoas para as quais eles transmitem estes conhecimentos não são apenas seus pacientes, mas também seus vizinhos, parentes ou amigos (DUARTE; SILVA; CARDOSO, 2007; WAI; CARVALHO, 2009). Isto gera ansiedade e insegurança, que se traduzem em estresse. Wai e Carvalho (2009) levantaram, ainda, a falta de privacidade dos ACS (advinda desta proximidade com a comunidade) como outro fator de estresse crônico. Além disso, esta posição expõe o agente a possíveis conflitos e dificuldades de relacionamento não apenas com pessoas da comunidade, mas também com os colegas membros da equipe de saúde, o que deve ser considerado na gênese da síndrome de burnout nesses profissionais (KLUTCHOVSKY et al., 2007).

Neste âmbito do relacionamento interpessoal dentro do ambiente de trabalho, Ferreira et al. afirmam haver um verdadeiro “jogo de disputa na equipe de saúde 
da família" (FERREIRA et al., 2009, p. 902). Segundo os autores, o ACS é representado no imaginário dos outros integrantes da equipe como o trabalhador manual, aquele que, desprovido de um conhecimento especializado em saúde, realiza um trabalho de menor valor. A principal consequência prática desta forma de pensar seria a exclusão do ACS dos processos de tomada de decisão (FERREIRA et al., 2009). Sem dúvidas, uma vez percebida pelo agente, esta atitude constituir-se-ia em uma significativa fonte de estresse. Em adição, o fato dos demais membros da equipe serem portadores de um maior nível educacional, salarial e de prestígio social é, por si só, outra fonte de estresse para os ACS (VASCONCELLOS; COSTA-VAL, 2008).

Por fim, deve-se lembrar de que o ACS é mais um trabalhador da saúde e que, portanto, está também exposto aos clássicos estressores atribuídos aos outros profissionais da área. Os agentes estão constantemente em contato com pessoas em estado de sofrimento e angústia, com pacientes moribundos e até com a morte. Ao resgatar-se que o ACS tem uma aproximação maior com a população, é de se esperar que a convivência com estas situações seja ainda mais impactante para este profissional.

Diante desta ampla teia de possíveis situações geradoras de estresse crônico no ambiente e na atuação profissional do ACS, é importante que se entenda como a formação deste trabalhador se relaciona, positiva ou negativamente, com o surgimento da síndrome de burnout.

Segundo a Portaria no 648 -GM, de 28 de março de 2006, toda a equipe de saúde da família deve passar por um curso introdutório, que deve iniciar-se em até três meses após a implantação da Unidade de Saúde da Família, ficando sua realização a cargo da Secretaria $\mathrm{Mu}-$ nicipal de Saúde (BRASIL, 2006a). Em seu Caderno de Atenção Básica no 2 , o Ministério da Saúde recomenda que este curso, orientado por uma metodologia ativa de ensino, contenha informações sobre: os princípios e as diretrizes da ESF e do SUS; o diagnóstico sociocultural e demográfico da comunidade; os sistemas de informação em saúde; e noções de trabalho em equipe e intersetorialidade (BRASIL, 2000b). O Ministério recomenda, ainda, que a equipe vivencie um processo de educação continuada, por meio de módulos direcionados às necessidades levantadas pelos próprios profissionais e pela comunidade atendida (BRASIL, 2000a).

Na prática, o processo de capacitação dos ACS é muito variável (BORNSTEIN; STOTZ, 2008) e, por vezes, insuficiente (SILVA; DALMASO, 2002; TOMAZ, 2002; SILVA; CARDOSO, 2007; AZAMBUJA et al., 2007; SILVA, 2001; BACHILLI; SCAVASSA; SPIRI, 2008). Esta afirmação está principalmente pautada na carência de uma formação que abranja conhecimentos da área das ciências humanas (SILVA; DALMASO, 2002; TOMAZ, 2002; BACHILLI; SCAVASSA; SPIRI, 2008). No contexto da prevenção da síndrome do esgotamento profissional, são justamente estes conhecimentos os mais importantes à formação do ACS. Segundo Duarte, Sil- va e Cardoso (2007) e, ainda, Bachilli, Scavassa e Spiri (2008), é por meio de uma educação que aborde relacionamento humano, liderança, autonomia, questões psicológicas relacionadas ao trabalho e outros temas afins que o ACS poderá enfrentar melhor as referidas situações estressantes encontradas no seu dia a dia. Wai e Carvalho (2009) defendem ainda que é preciso haver uma constante supervisão dos ACS por parte dos enfermeiros das USF, atentando para eventuais falhas na capacitação dos agentes e os auxiliando a lidar com as adversidades do trabalho. Por fim, faz-se necessário, durante a capacitação dos ACS, conscientizá-los de que sua profissão tem limitações e que os problemas socioeconômicos enfrentados pela comunidade extrapolam estes limites, sendo sua resolução de responsabilidade intersetorial (AZAMBUJA et al., 2007).

Tendo em vista o que foi apresentado sobre a síndrome de burnout e sua relação com o processo de trabalho e a formação dos ACS, cumpre, então, abordar as estratégias de enfrentamento utilizadas por estes profissionais. Estas estratégias consistem nos artifícios usados pelos agentes para lidar com os estressores crônicos presentes no seu ambiente de trabalho, combatê-los ou os amenizar. Pode-se citar: a prática de atividades físicas (que produz endorfinas e provoca uma sensação de bem-estar); o consumo de uma alimentação "antiestresse" saudável (que visa suprir os nutrientes gastos nas situações de estresse); a realização de atividades de lazer, das mais variadas; o uso de técnicas de relaxamento e meditação - que diminuem a frequência cardíaca e o consumo de oxigênio, reduzindo a ansiedade (SOUZA; SILVA, 2002).

A busca por suporte social em amigos, parentes, grupos de apoio e crenças religiosas é outra estratégia de enfrentamento (VASCONCELLOS; COSTA-VAL, 2008; TELLES; PIMENTA, 2009). O incentivo, por parte dos gestores, e a disponibilização de tempo e espaço para a realização das práticas de relaxamento e lazer são um ponto de grande importância neste combate ao estresse laboral (SOUZA; SILVA, 2002), minimizando os danos aos profissionais e, consequentemente, melhorando os serviços prestados à população (CAMELO; ANGERAMI, 2004; SILVA, 2008). Finalmente, existem também as medidas terapêuticas, como as formas de intervenção psicológica e comportamental (TELLES; PIMENTA, 2009).

Telles e Pimenta (2009) e Vasconcellos e Costa-Val (2008) notaram em suas pesquisas que é recorrente entre os ACS a busca por apoio religioso e outras formas de apoio social no combate ao estresse. Telles e Pimenta (2009) observaram ainda que as principais estratégias relatadas pelos ACS em seu estudo foram aquelas focadas no problema, por meio das quais o profissional tenta encarar e resolver (ou aprender a lidar com) a situação estressora. Esses autores apontaram que os ACS entrevistados não tinham o hábito de praticar exercícios físicos (TELLES; PIMENTA, 2009). Wai e Carvalho (2009) perceberam em seu estudo outras estratégias, além das citadas, como a prática de atividades de lazer e meditação, a partilha de experiências com os colegas 
de equipe, a tentativa de encarar positivamente a situação ou, em outra linha, de se desprender emocionalmente do trabalho, a busca por formas de psicoterapia ou assistência social e o uso de antidepressivos. Algumas formas de enfrentamento não foram mencionadas nos artigos como estratégias usadas pelos ACS, o que pode significar uma falta de conhecimento dos reais benefícios dessas práticas e atitudes no manejo do estresse crônico e, por conseguinte, na prevenção da síndrome de burnout.

\section{Considerações finais}

No presente ensaio, buscou-se discutir aspectos apresentados na literatura levantada como fatores de risco para o surgimento da síndrome de burnout presentes na profissão e na capacitação dos ACS. A função de mediador/tradutor entre a equipe e a comunidade, a proximidade física e, principalmente, emocional com a população e o contato direto com os problemas macroestruturais do território foram levantados como potenciais fontes de estresse que estão naturalmente presentes na prática diária deste profissional.

Percebe-se, assim, que a maioria das fontes de estresse na ocupação do ACS não pode ser modificada ou evitada, uma vez que se constituem em aspectos essenciais à atuação desse profissional. Por isso, faz-se mister que estes fatores sejam devidamente abordados na formação do agente. Se o estresse ocupacional nestes casos deve-se em grande parte ao choque provocado por estas situações em um agente despreparado para lidar com elas, a compreensão dos riscos inerentes ao seu processo de trabalho e das limitações de sua função são importantes formas de prevenção do esgotamento profissional. Nesta linha de pensamento, é também de suma importância que sejam claras e bem delimitadas aos agentes, aos demais membros da equipe, aos gestores e à população as reais atribuições do ACS. Tomaz (2002) aponta o cuidado que se deve ter em não promover uma "super-heroização" ou "romantização" do ACS, incutindo-lhe responsabilidades e papéis que extrapolam estas atribuições por lei definidas. O ACS é, indubitavelmente, um profissional essencial à ESF, mas é, ao mesmo tempo, apenas mais um membro da equipe, com afazeres preestabelecidos que completam os dos demais membros.

O processo de formação deste profissional, por sua vez, deixa a desejar. Ainda que não se questione aqui o aspecto técnico desta formação, percebeu-se na literatura referências a um déficit de conhecimentos humanísticos na preparação do ACS. Esta carência priva o agente dos conhecimentos necessários ao correto enfrentamento das situações de estresse presentes em seu trabalho e, especialmente, daquelas que envolvem relações sociais.

Quanto às estratégias de enfrentamento, parece haver, em parte, um desconhecimento por parte dos ACS da ampla gama de atividades que podem ser desenvol- vidas com o intuito de minimizar os efeitos do estresse laboral. Há também uma negligência por parte dos gestores ao não abordarem estas questões com os trabalhadores da saúde da família. É importante que ambos, os ACS e os seus superiores, estejam interessados em prevenir o surgimento da síndrome de burnout. Neste sentido, Trindade (2007) sugere a instituição de programas de apoio social e de estímulo e melhoramento do trabalho em equipe, bem como que o planejamento dos serviços a serem desenvolvidos seja feito com auxílio de todos os membros das USF, visando promover seu crescimento profissional e individual e, consequentemente, melhorar a assistência prestada. Murta (2005), ao investigar programas de manejo de estresse ocupacional, afirma, ainda, que existem evidências consistentes de que a utilização de intervenções focadas no indivíduo (sessões de relaxamento, fornecimento de informações a respeito de causas e consequências de estresse, treino em solução de problemas etc.) produz efeitos benéficos para a sua saúde.

O levantamento destes aspectos é um passo essencial para que se pense em mudanças na formação destes profissionais, nas suas condições de vida e trabalho e no apoio (preventivo e terapêutico) destinado a eles. Os benefícios deste enfoque recairão não apenas sobre a saúde dos ACS, mas também sobre a população assistida por eles. Acreditamos ser este um dos principais avanços obtidos com este e outros trabalhos similares: despertar a atenção, inicialmente, para os fatores de risco da síndrome de burnout existentes na profissão do agente, de forma a tomar atitudes preventivas adequadas e; despertar a atenção, também, para as manifestações do esgotamento profissional nestes sujeitos de forma a abordá-lo precocemente.

Acreditamos, ainda, que o presente estudo contribuiu tanto para reunir e apontar algumas das relações já estabelecidas entre o burnout e os ACS nos artigos específicos sobre o tema, quanto para discutir outros possíveis pontos de encontro entre estes dois temas, destacando aspectos do processo de formação, das atribuições e da atuação cotidiana dos agentes que são classicamente entendidos como fatores de risco para a síndrome. Por outro lado, pôde-se constatar que há, no momento, número ainda insuficiente de pesquisas de campo buscando comprovar tais relações. Há que se notar, assim, que as informações aqui levantadas têm seu limite imposto por tal comprovação prática ainda deficitária.

Portanto, com o intuito de que se promovam evidências para que seja possível generalizar tais constatações e, consequentemente, dar ainda mais força às mudanças acima mencionadas, é importante que mais trabalhos de campo associando ACS e síndrome de burnout sejam desenvolvidos. As questões trabalhadas neste ensaio precisam ser averiguadas em pesquisas empíricas com ACS, de forma a possibilitar uma consolidação destes conhecimentos e uma futura mudança na abordagem destes profissionais. 


\section{Contribuições de autoria}

Maia, L. D. de G.: contribuiu para a formação da ideia inicial do ensaio, auxiliou na formulação e na delimitação do projeto, procedeu à pesquisa de artigos e demais materiais que compuseram o referencial teórico do ensaio, participou da leitura e da análise das referências levantadas, agiu como redator do escopo do ensaio e atuou na avaliação crítica e aprovação do texto final. Silva, N. D.: contribuiu para a formação da ideia inicial do ensaio, auxiliou na formulação e na delimitação do projeto, procedeu à pesquisa de artigos e demais materiais que compuseram o referencial teórico do ensaio, participou da leitura e da análise das referências levantadas, agiu como corredator do escopo do ensaio e atuou na avaliação crítica e na aprovação do texto final. Mendes, P. H. C.: contribuiu para a formação da ideia inicial do ensaio, auxiliou na formulação e na delimitação do projeto, participou da leitura e da análise das referências levantadas e atuou na avaliação crítica e na aprovação do texto final.

\section{Referências}

AZAMBUJA, E. P. et al. Significados do trabalho no processo de viver de trabalhadoras de um Programa de Saúde da Família. Texto Contexto Enfermagem, Florianópolis, v. 16, n. 1, p. 71-79, jan./mar. 2007.

BACHILLI, R. G.; SCAVASSA, A. J.; SPIRI, W. C. A identidade do agente comunitário de saúde: uma abordagem fenomenológica. Ciência \& Saúde Coletiva, v. 13, n. 1, p. 51-60, 2008.

BORNSTEIN, V. J.; STOTZ, E. N. Concepções que integram a formação e o processo de trabalho dos agentes comunitários de saúde: uma revisão da literatura. Ciência \& Saúde Coletiva, v. 13, n. 1, p. 259268, 2008.

BRASIL. Decreto nº 3.048, de 06 de maio de 1999. Aprova o regulamento da Previdência Social, e dá outras providências. Diário Oficial [da] República Federativa do Brasil, Brasília-DF, 7 maio 1999. Disponível em: <http:/www010.dataprev.gov.br/ sislex/paginas/23/1999/3048.htm >. Acesso em: 28 abr. 2010.

. Ministério da Saúde. Secretaria de Políticas de Saúde. Departamento de Atenção Básica. Educação Permanente. Brasília: Ministério da Saúde, 2000a.

. Ministério da Saúde. Secretaria de Políticas de Saúde. Departamento de Atenção Básica. Treinamento Introdutório. Brasília: Ministério da Saúde, 2000b.

. Portaria nº 648-GM, de 28 de março de 2006. Aprova a Política Nacional de Atenção Básica, estabelecendo a revisão de diretrizes e normas para a organização da Atenção Básica para o Programa Saúde da Família (PSF) e o Programa Agentes Comunitários de Saúde (PACS). Brasília, 28 mar. 2006a. Disponível em: <http:/dtr2001.saude.gov.br/sas/PORTARIAS/ Port2006/GM/GM-648.htm> Acesso em: 28 abr. 2010.

. Lei $\mathrm{n}^{\circ}$ 11.350, de 5 de Outubro de 2006. Regulamenta o § 5º do art. 198 da Constituição, dispõe sobre o aproveitamento de pessoal amparado pelo parágrafo único do art. $2^{\circ}$ da Emenda Constitucional $\mathrm{n}^{\circ}$ 51, de 14 de fevereiro de 2006, e dá outras providências. Diário Oficial [da] República Federativa do Brasil, Brasília-DF, 6 out. 2006b. Disponível em: < http:// www010.dataprev.gov.br/sislex/paginas/42/2006/11350. htm >. Acesso em: 28 abr. 2010.

CAMELO, S. H. H.; ANGERAMI, E. L. S. Sintomas de estresse nos trabalhadores atuantes em cinco núcleos de saúde da família. Revista Latino-americana de Enfermagem, v. 12, n. 1, p. 14-21, jan./fev. 2004.

CASTILLO RAMÍREZ, S. El Síndrome de Burn Out o Síndrome de agotamiento professional. Medicina Legal de Costa Rica, Heredia, v. 17, n. 2, mar. 2001.

DIAS, W. F. Meios de trabalho-espaço de vida: a atividade de trabalho dos agentes comunitários de saúde no município de Juiz de Fora, MG. 2008. 103 f. Dissertação (Mestrado em Ciências na área de Saúde Pública)-Escola Nacional de Saúde Pública, Fundação Oswaldo Cruz, Rio de Janeiro, 2008.

DUARTE, L. R.; SILVA, D. S. J. R.; CARDOSO, S. H. Construindo um programa de educação com agentes comunitários de saúde. Interface: Comunicação, Saúde, Educação, v. 11, n. 23, p. 439-47, set./dez. 2007.

FERREIRA, V. S. C. et al. Processo de trabalho do agente comunitário de saúde e a reestruturação produtiva. Cadernos de Saúde Pública, Rio de Janeiro, v. 25, n. 4, p. 898-906, abr. 2009.

FIGUEIREDO, I. M. et al. Qualidade de vida no trabalho: percepções dos agentes comunitários de equipes de saúde da família. Revista Enfermagem UERJ, Rio de Janeiro, v. 17, n. 2, p. 262-267, abr./jun. 2009.

FREUDENBERGER, H. J. Staff burnout. Journal of Social Issues, v. 30, n. 1, p. 159-165, 1974.

KLUTCHOVSKY, A. C. G. C. et al. Avaliação da qualidade de vida geral de agentes comunitários de saúde: a contribuição relativa das variáveis sociodemográficas e dos domínios da qualidade de vida. Revista de Psiquiatria do Rio Grande do Sul, v. 29, n. 2, p. 176-183, 2007.

LINZER, M. et al. Organizational climate, stress, and error in primary care: the MEMO Study. In: CLANCY C. (Ed.). Advances in patient safety: from research to implementation. Rockville: Agency for 
Healthcare Research and Quality, 2005. Disponível em: <http://www.ncbi.nlm.nih.gov/bookshelf/ br.fcgi?book=aps\&part=A194> . Acesso em: 28 abr. 2010.

MASLACH, C. Comprendiendo el burnout. Ciencia $\mathcal{F}$ Trabajo, v. 11, n. 32, p. 37-43, abr./jun. 2009.

MURTA, S. G. Programas de manejo de estresse ocupacional: uma revisão sistemática da literatura. Revista Brasileira de Terapia Comportamental e Cognitiva, São Paulo, v. 7, n. 2, p. 159-177, dez. 2005

NASCIMENTO, C. N. B. Análise do cumprimento das práticas dos agentes comunitários de saúde em municípios da região metropolitana do Recife. 2008. 160 f. Dissertação (Mestrado em Saúde Pública)Centro de Pesquisas Aggeu Magalhães, Fundação Oswaldo Cruz, Recife, 2008.

NASCIMENTO, E. P. L.; CORREA, C. R. S. O agente comunitário de saúde: formação, inserção e práticas. Cadernos de Saúde Pública, Rio de Janeiro, v. 24, n. 6, p. 1304-1313, jun. 2008.

NASCIMENTO, G. M.; DAVID, H. M. S. L. Avaliação de riscos no trabalho dos agentes comunitários de saúde: um processo participativo. Revista Enfermagem UERJ, Rio de Janeiro, v. 16, n. 4, p. 550-556, out./dez. 2008.

NUNES, M. O. et al. O agente comunitário de saúde: construção da identidade desse personagem híbrido e polifônico. Cadernos de Saúde Pública, Rio de Janeiro, v. 18, n. 6, p. 1639-1646, nov./dez. 2002.

ORGANIZAÇÃO MUNDIAL DA SAÚDE. CID-10: Classificação Estatística Internacional de Doenças e Problemas Relacionados à Saúde. 2008. Disponível em: <http:/www.datasus.gov.br/cid10/v2008/cid10. htm >. Acesso em: 28 abr. 2010.

SCHWARTZMANN, L. Estrés laboral, síndrome de desgaste (quemado), depresión: ¿estamos hablando de lo mismo? Ciencia $\&$ Trabajo, v. 6, n. 14, p. 174-184, out./dez. 2004.

SILVA, A. T. C. Esgotamento profissional e transtornos mentais comuns em agentes comunitários de saúde. Revista de Saúde Pública, v. 42, n. 5, p. 921-929, 2008.
SILVA, J. A. O agente comunitário de saúde do Projeto Qualis: agente institucional ou agente de comunidade? 2001. 231 f. Tese (Doutorado em Administração Hospitalar)-Departamento de Prática de Saúde Pública, Faculdade de Saúde Pública, Universidade de São Paulo, São Paulo, 2001.

SILVA, J. A.; DALMASO, A. S. W. O agente comunitário de saúde e suas atribuições: os desafios para os processos de formação de recursos humanos em saúde. Interface: Comunicação, Saúde, Educação, v. 6, n. 10, p. 75-96, fev. 2002.

SOUZA, W. C.; SILVA, A. M. M. A influência de fatores de personalidade e de organização do trabalho no burnout em profissionais de saúde. Estudos de Psicologia, Campinas, v. 19, n. 1, p. 37-48, jan./abr. 2002.

TELLES, S. H.; PIMENTA, A. M. C. Síndrome de burnout em ACS e estratégias de enfrentamento. Saúde e Sociedade, São Paulo, v. 18, n. 3, p. 467-478, 2009.

TOMAZ, J. B. C. O agente comunitário de saúde não deve ser um super-herói. Interface: Comunicação, Saúde, Educação, v. 6, n. 10, p. 75-94, fev. 2002.

TRIGO, T. R.; TENG, C. T.; HALLAK, J. E. C. Síndrome de burnout ou estafa profissional e os transtornos psiquiátricos. Revista de Psiquiatria Clínica, São Paulo, v. 34, n. 5, p. 223-233, 2007.

TRINDADE, L. L. O estresse laboral da equipe de saúde da família: implicações para saúde do trabalhador. 2007. 103 f. Dissertação (Mestrado em Enfermagem)Escola de Enfermagem, Universidade Federal do Rio Grande do Sul, Porto Alegre, 2007.

VASCONCELLOS, N. P. C.; COSTA-VAL, R. Avaliação da qualidade de vida dos agentes comunitários de saúde de Lagoa Santa - MG. Revista de APS, v. 11, n. 1, p. 17-28, jan./mar. 2008.

WAI, M. F. P.; CARVALHO, A. M. P. O trabalho do agente comunitário de saúde: fatores de sobrecarga e estratégias de enfrentamento. Revista Enfermagem UERJ, Rio de Janeiro, v. 17, n. 4, p. 563-568, out./dez. 2009. 